\title{
Visual Fields
}

\section{Maps, Place, and Tattoos}

Jonathan F. Lewis

ЦLewis@ben.edu

Benedictine University

Tattooing has dramatically increased in popularity over the past two decades, with more than one third of young Americans now estimated to possess at least one tattoo. Accompanying this expanded acceptability has been an expanding diversity of tattoo designs, including maps, map iconography, city skylines, landscape depictions, and other expressions of a sense of place. Examples of typical map tattoos taken from more than 600 images I have collected are shown.

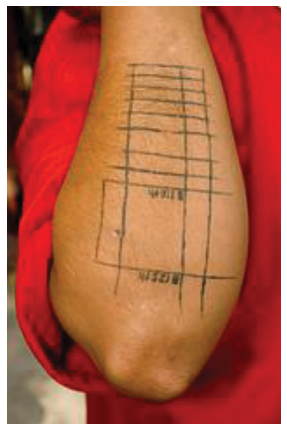

Courtesy Rickey, from Rickey.org ${ }^{1}$
Pride of place is a common motivation behind map tattoos, as evidenced by remarks given by those who obtain them. Small, simple designs cost little to acquire, making them attractive to individuals with limited income. Here, for example, is a tattoo of streets in East Harlem.

State outlines are also quick and inexpensive, with a heart or star marking the owner's hometown:

Courtesy Paul Perry

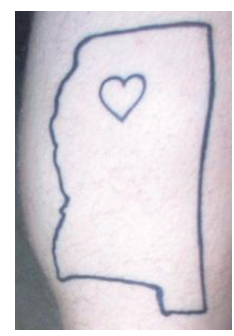

Individuals having more time and money may opt for elaborate designs, such as this skyline of Chicago:

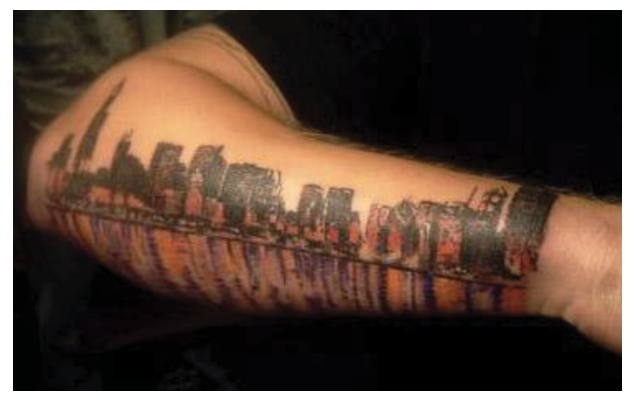

Courtesy David Allen

Among immigrants, this type of tattoo may take the form of a simple outline of their country of origin, its interior filled with the colors of that nation's flag. Proud of their non-native origins, yet longing to become American, some immigrants include maps of both their country of origin and of adoption destination. Take, for

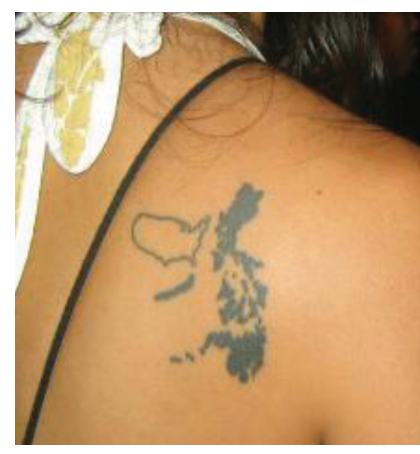

Courtesy Elmer ${ }^{2}$ example, this FilipinoAmerican's tattoo.

While sometimes appearing by itself, Earth is usually incorporated into larger designs, such as the popular U.S. Marine Corps logo, which features a globe at its center. Marines having this type of tattoo describe acquiring them as an expression of loyalty to an organization to which they proudly belong.

People having tattoos featuring compasses sometimes explain them as statements about the need for proper guidance in life or as symbolizing the importance of family to providing a sound sense of self: "I thought of a compass, and then of what I call a compass star-an 8 pointed nautical star.

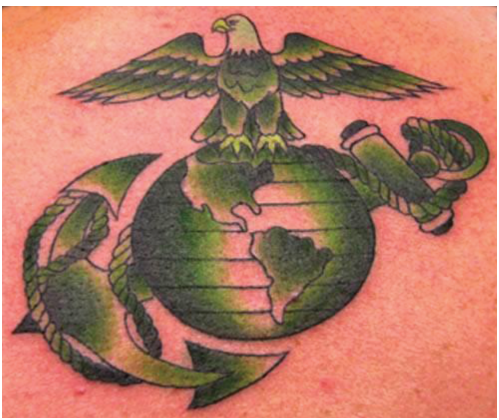

Courtesy Sgt. Grit A compass, as my family has been to me" (Stephanie C).

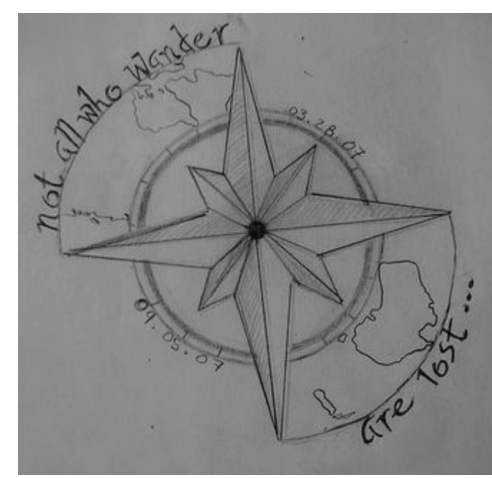

Compass design, courtesy saskatchewanpirate 
Earth also appears in tattoos depicting issues that transcend national borders.

As an individual with such a tattoo put it, "I chose it because of my love for the environment and the planet on which I live. . . . It's a part of me mentally; why not make it a part of me physically?" (Graham).

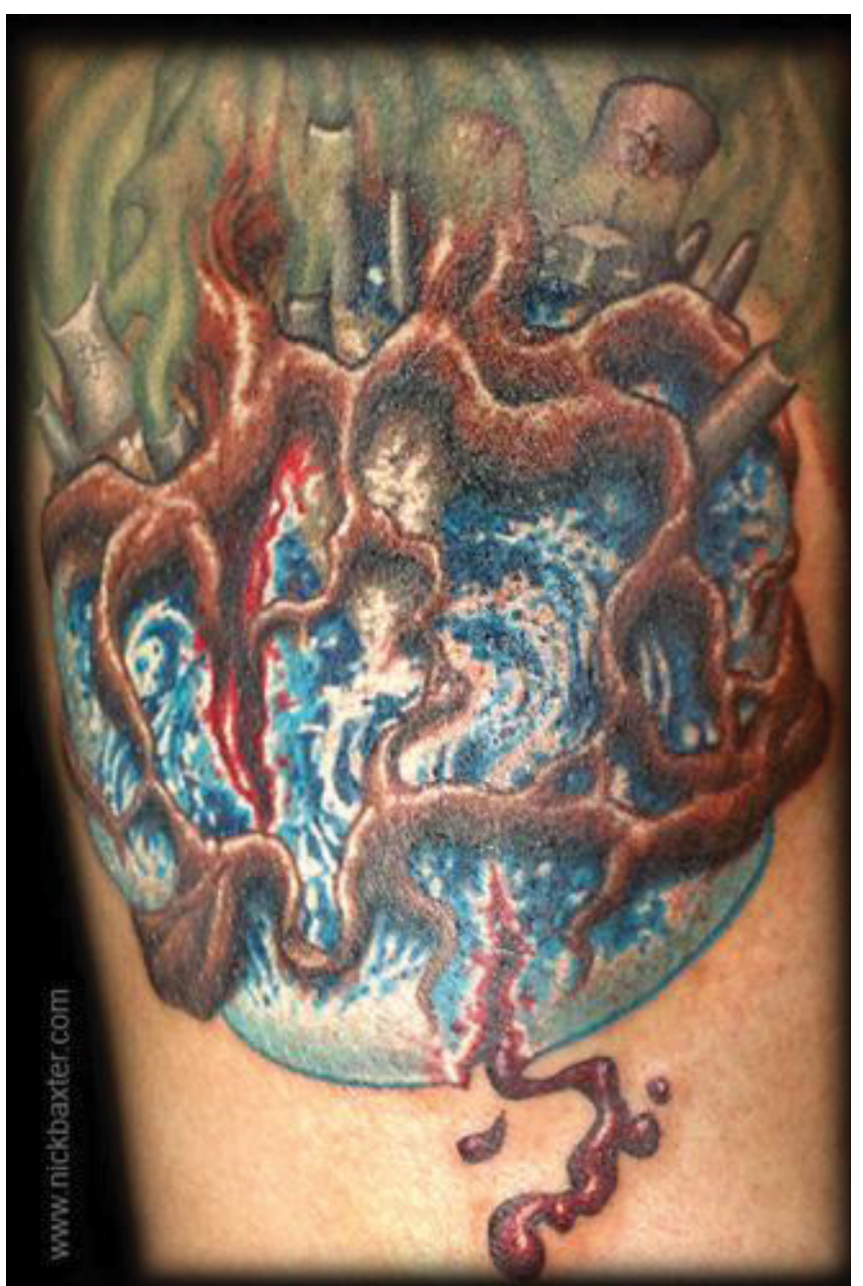

"Regarding the map-i have always loved maps; i love looking at them and $\mathrm{i}$ [loved] using them-from road maps to satellite images, they all intrigue me" (hotash).

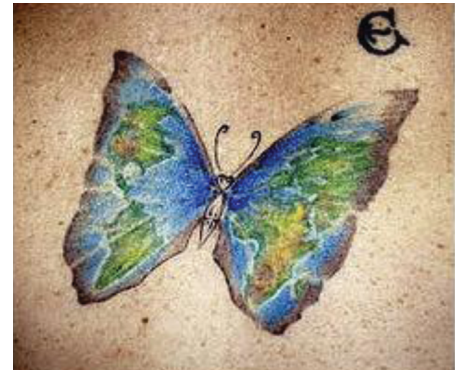

Courtesy hotash

Courtesy Nick Baxter

Endnotes

${ }^{1}$ All bearers of a tattoo wished to remain anonymous.

${ }^{2}$ Anonymity was requested when only one contributor name is listed. 